\title{
Hacia el origen
}

Juliana Rojas

- Cuál es la magia que emplea Carlos Badillo (México, 1978) para desatar sus bocetos de tal modo que reaparecen como vestigios en atmósferas personalí-

simas sujetas a las leyes de un sistema propio de organización y significado?, ¿dónde se gestan las trazas para transformarlas y emprender la fuga de sus fuerzas internas? Hay en el oficio del artista un deseo que lo lleva a explorar aquellos instantes de creación pulsional y lo cotidiano en busca de residuos para ver lo invisible, materializar lo inasible y decir lo indecible. Badillo lo hace transmutando el origen de sus propias emociones contenidas, expresadas bajo una estética de lo primigenio y, aun así, no alcanza a decirlo del todo. Pese a ello, continúa aludiendo al misterio.

Los títulos de algunas de las piezas que comprenden esta selección (Entrañas, Huella de hombre, Especies híbridas) pueden servirnos como una puerta o, al menos, una ventana entreabierta para dirigirnos a un cuerpo de obra que recurre a un tipo de destrucción transformadora de su propio proceso de trabajo. Marcados por el rigor y la minuciosidad — por paradójico que parezca一, los elementos que conforman el presente repertorio visual han sido extraídos principalmente de las propias libretas de bocetos del artista que refieren secuencias creativas de esparcimiento personal. Del mismo modo que se protege el valor de cualquier tesoro, pese a su larga trayectoria, Badillo había mantenido hasta ahora estas obras en resguardo, en secreto. Mediante la materialización de lo residual, por primera vez se nos ofrece un universo híbrido de huellas de inusitada belleza que además posee un alto grado de intimidad. La reconstrucción de los elementos aludidos (principalmente, figura humana y animales) a los que dota de una cualidad arcaica, deviene en una suerte de imaginería ancestral o, si se prefiere, en evocaciones de ausencia de temporalidad, tema y estilo como marca distintiva producto de su búsqueda de liberación de parámetros e imposiciones. 
Se trata, en cierto modo, de una suerte de compendio íntimo constituido por vestigios psíquicos mezclados con la esencia de lo humano, que persigue reiteradamente mediante la transmutación de las fuerzas vitales en piezas de factura impecable. Carlos Badilo, mediante un sistema de leyes propias, opera con lo velado de los rastros. Es el artista un chamán que busca el centro del misterio más profundo de nuestra existencia y, una vez descubierto, nos lo devuelve de tal modo que en cada obra sólo tenemos un indicio. El creador borra el sendero trazado para llegar a este centro de tal modo que nos obliga a emprender un camino propio.

Las huellas que han hecho posible la realización de estos trabajos, sin embargo, al igual que los conjuros, conservan toda la potencia de las energías sagradas, ancestrales y conceptuales. Las piezas que aquí se presentan son sumamente disímiles entre sí, quizás a modo de reafirmación no sólo de la propia libertad creativa del artista sino también de su magia.

Los recursos plásticos utilizados por Carlos Badillo están determinados por tres diferentes técnicas que conforman categorías: dibujo simple, dibujo de arte y obra pictórica. Estas agrupaciones exploran estéticas de lo absoluto y, sin embargo, contrario a cualquier especulación, no guardan ninguna correspondencia cronológica entre ellas ni tampoco devienen en transición alguna del dibujo a la pintura. Su organización corresponde a una expansión orgánica, haciendo uso de diversos materiales y empleando la libertad como la marca distintiva de quien se sabe capaz de oficiar ritos de modo repetitivo y ejecuta ceremonias que acercan la naturaleza, lo frágil, lo eterno, lo simple y lo complejo.

Esa transición —y fuga — entre la referencia de la obra previa de Carlos Badillo (determinada por la ilustración) hacia la búsqueda del absoluto va ensanchando las posibilidades de los materiales y las fronteras entre la pintura y el dibujo. Sin duda, el artista construye puentes en donde no los había y destruye aquellas barreras que existían. Es quizás por eso que no hay un tema central en sus imágenes. Por ello, igual puede presentar un dibujo realizado con tinta, con lápiz de carbón o una pieza elaborada con óleo o pintura acrílica.

El gesto de transmutar el universo íntimo o elementos comunes equivale a una postura mística. Badillo pareciera liberarse de la densa complejidad de la existencia y del peso de las categorizaciones mediante la acción de su obra. Pero simultáneamente, usa el arte para mostrar la complejidad de las cosas simples y la dinámica cíclica de la vida.

Quizás esas oscilaciones de la forma que borran los vestigios o los constituyen como nuevos a partir de la transmutación de ejercicios previos en piezas terminadas, el acontecimiento y la nada, la mancha y la línea, el origen y el fin, estén anudadas por una sola materia invisible ante la cual se subyugan y de la que intentan asirse: el origen. 


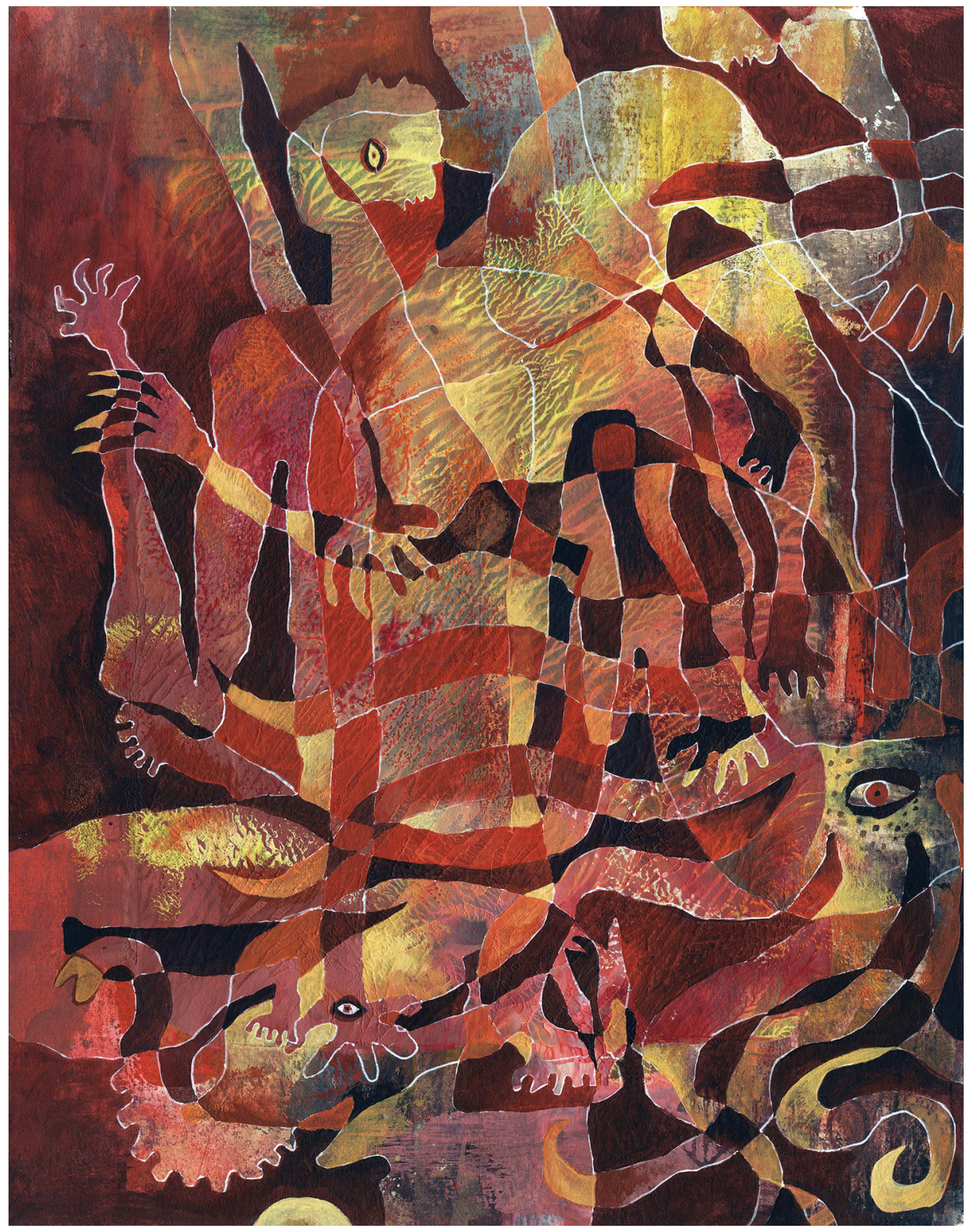

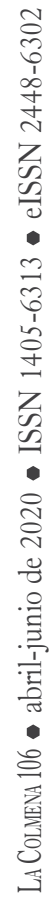

Hombre y pulpo, de la serie Obra pictórica (2018). Acrílico sobre papel: Carlos Alberto Badillo-Cruz. Prohibida su reproducción en obras derivadas. 


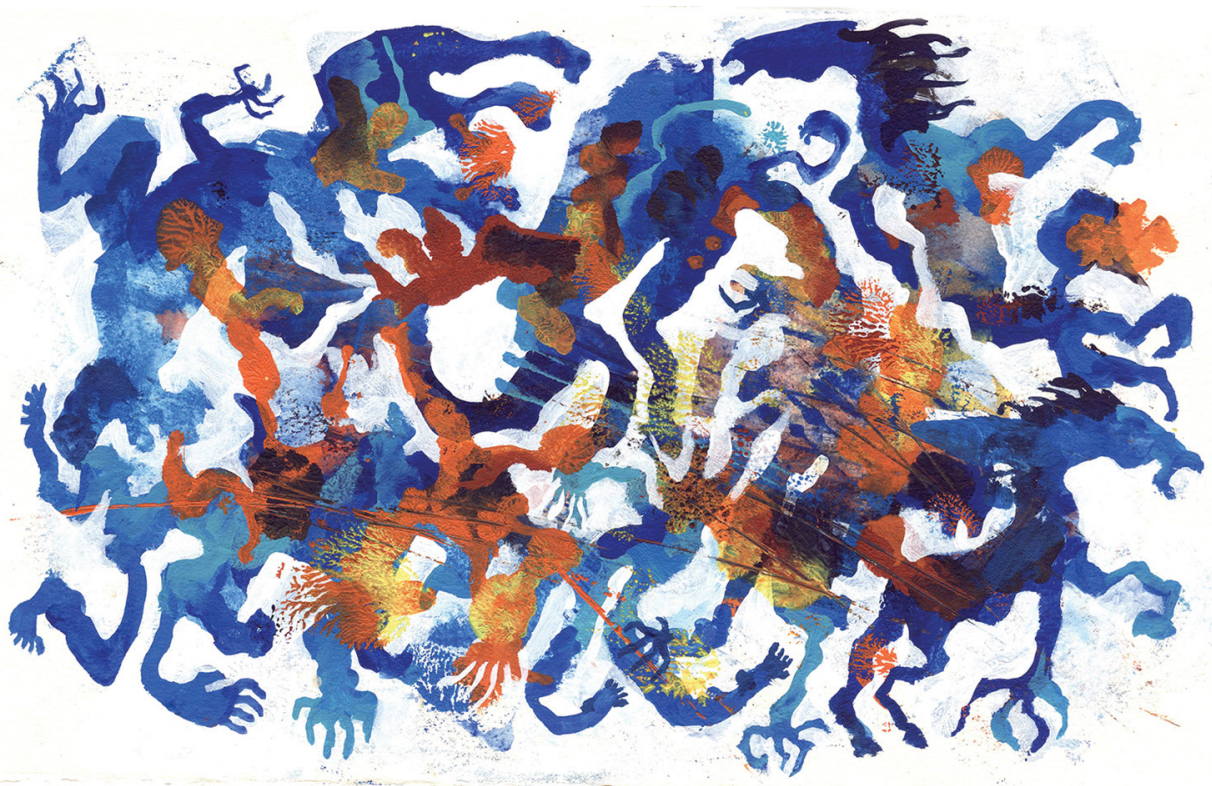

Equinos y hombres, de la serie Obra pictórica (2018). Acrílico sobre papel: Carlos Alberto Badillo-Cruz. Prohibida su reproducción en obras derivadas.

Dibujo simple, como su nombre lo indica, agrupa un conjunto de dibujos elaborados con tinta sobre papel, conformados por una bitácora actualizada. Allí donde la mayoría de los artistas escapa y de donde se suele partir hacia un nuevo nivel de creación, Badillo busca retornar, puesto que efectúa la operación contraria, sobre todo, como indagación interior y autocomplacencia. En Dibujo simple, el artista rescata las semillas que surgen de sus bosquejos, restituyéndolos abiertamente y devolviéndolos a la cualidad ontológica de una obra que surge y es por sí misma. Al regresar a esta primera etapa de creación el ciclo se cierra hasta llegar al sustrato más oscuro de la psique del artista, literalmente el propio origen de su proceso de creación, de sus pensamientos, sentimientos y antepasados, y de esta manera subvierte los órdenes de construcción de producción, convirtiendo el inicio en fin y el proceso en resultado, es decir, invirtiendo y desdibujando las jerarquías de la imagen: transforma la simplicidad del ejercicio cotidiano en obra terminada y el gesto de lo espontáneo en la esencia de su creación.

La aparente sencillez de estas imágenes, realizadas mediante tinta sobre papel, es también signo del desplazamiento del propio cuerpo que traza y de la línea de tinta continua que se adhiere a la superficie del papel. A manera de bestiario, la hibridación entre lo humano y lo animal se acerca a la vez al límite de la disolución de la forma y el fondo, en donde se puede apreciar, como su nombre lo indica, una simplicidad que, sin embargo, desemboca en un conjunto de dibujos que, a manera de red, nos atrapan y no nos dejan escapar. 
La sensorialidad se ve intensificada al igual que los materiales empleados en la segunda agrupación: Dibujo de arte. Son obras realizadas con trazos firmes y líneas continuas que terminan por generar un efecto sobrecogedor por la unión de fuerzas que las componen. En estas imágenes, todas las cosas que se representan se entrecruzan y pueden animarse, convertirse en personajes con capacidad de acción y transformarse en paisajes interminables.

Las marcas localizadas en estas piezas evocan varias acciones simultáneas que el artista señala en una suerte de espacio íntimo como parte de un proceso de depuración. Estos indicios generan ritmos y hacen que dichas marcas resuenen como si de un mantra se tratara.

El simbolismo milenario y la caótica complejidad de la vida se ven reflejados en la tercera agrupación: Obra pictórica. En ella, humanos, animales, barcas, signos del sujeto nómada se entrecruzan y superponen hasta fusionarse, así como también se enfatiza la relación entre lo gráfico y lo pictórico. La conciencia y el deseo de la perdurabilidad del arte, y la búsqueda constante por contener a la vez la fragilidad y lo infinito, aparecen en esta serie. La poética de lo cotidiano ofrece el silencio de la nada que contiene las fases de la vida y los retornos, nos recuerda imágenes arcaicas, rupestres, que nos remontan a los orígenes del hombre, aborda una concepción muy semejante a la visión cíclica de nuestros antepasados.

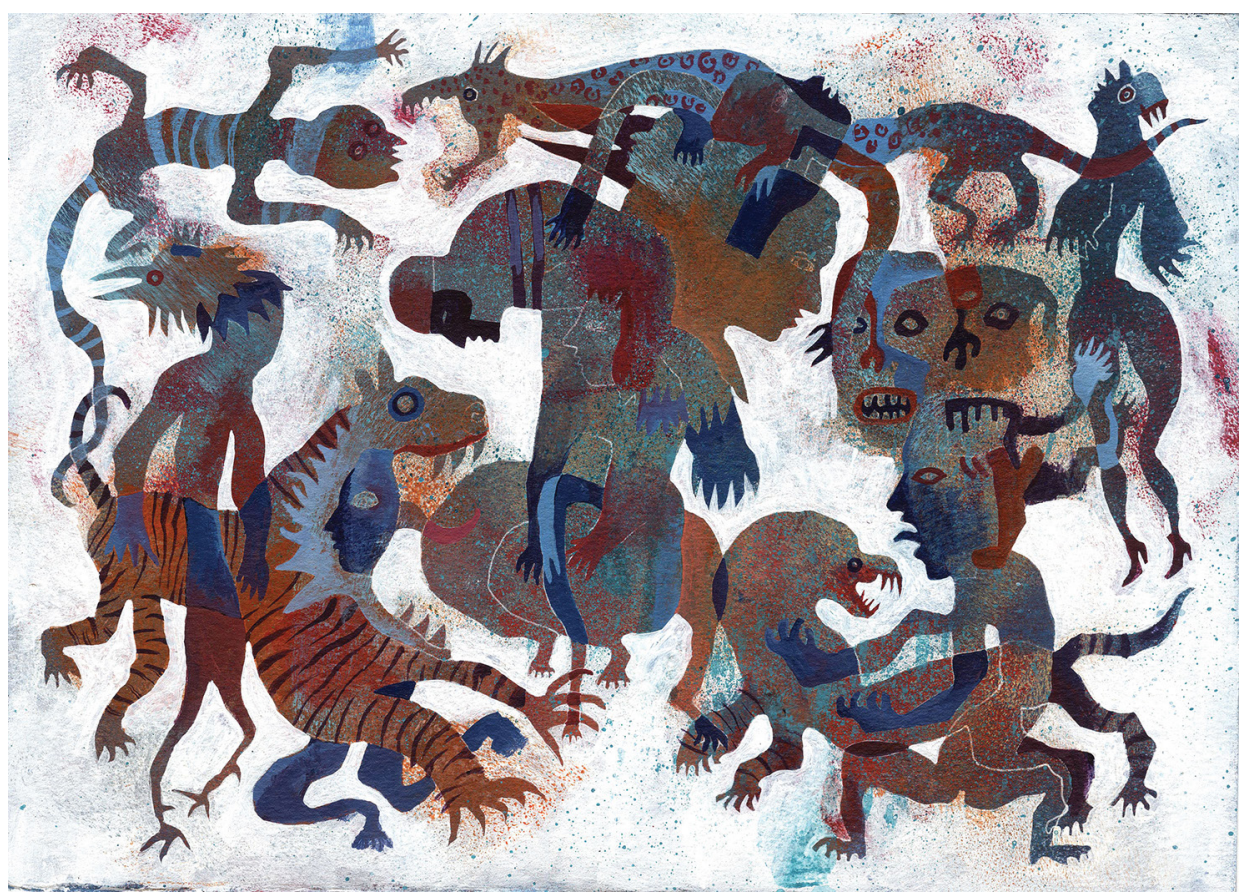

Noche de nahuales 2, de la serie Obra pictórica (2018). Acrílico sobre papel: Carlos Alberto Badillo-Cruz. Prohibida su reproducción en obras derivadas. 


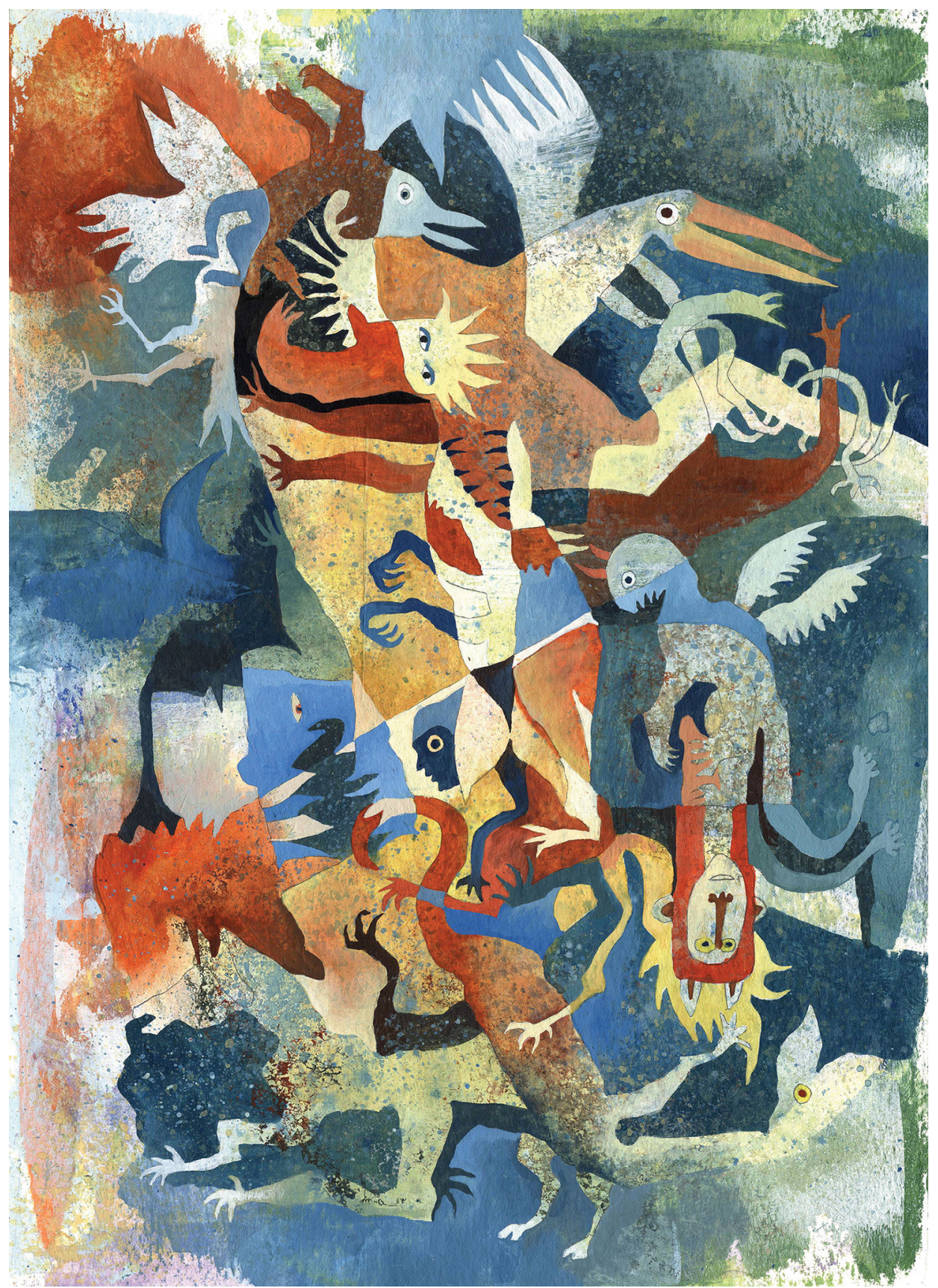

En el cuerpo de un ave, de la serie Obra pictórica (2017). Acrílico sobre papel: Carlos Alberto Badillo-Cruz. Prohibida su reproducción en obras derivadas. 
La estructuración de la identidad mediante la mirada, su búsqueda y la muerte simbólica de trabajos previos, resulta determinante en la construcción del lenguaje de Carlos Badillo, el cual es irrepetible en la medida en que lo ha extraído de las propias fuerzas del inconsciente y lo ha vuelto signo y materia con procesos de una minuciosidad que podría llevar al límite. El artista asume el reto de la creación plástica sujetándose a su propio deseo, donde encuentra las intempestivas luces que alumbrarán el camino hacia nuevas obras y que, de algún modo, empiezan a allanar el terreno para albergar imágenes que surgirán en un futuro.

En conjunto, el artista ejecuta una serie de subversiones a modo de eje temporal que estructura en su propio lenguaje y, según revela él mismo, de premoniciones y profecías basadas en lo pasado que se prolongan en obras futuras.

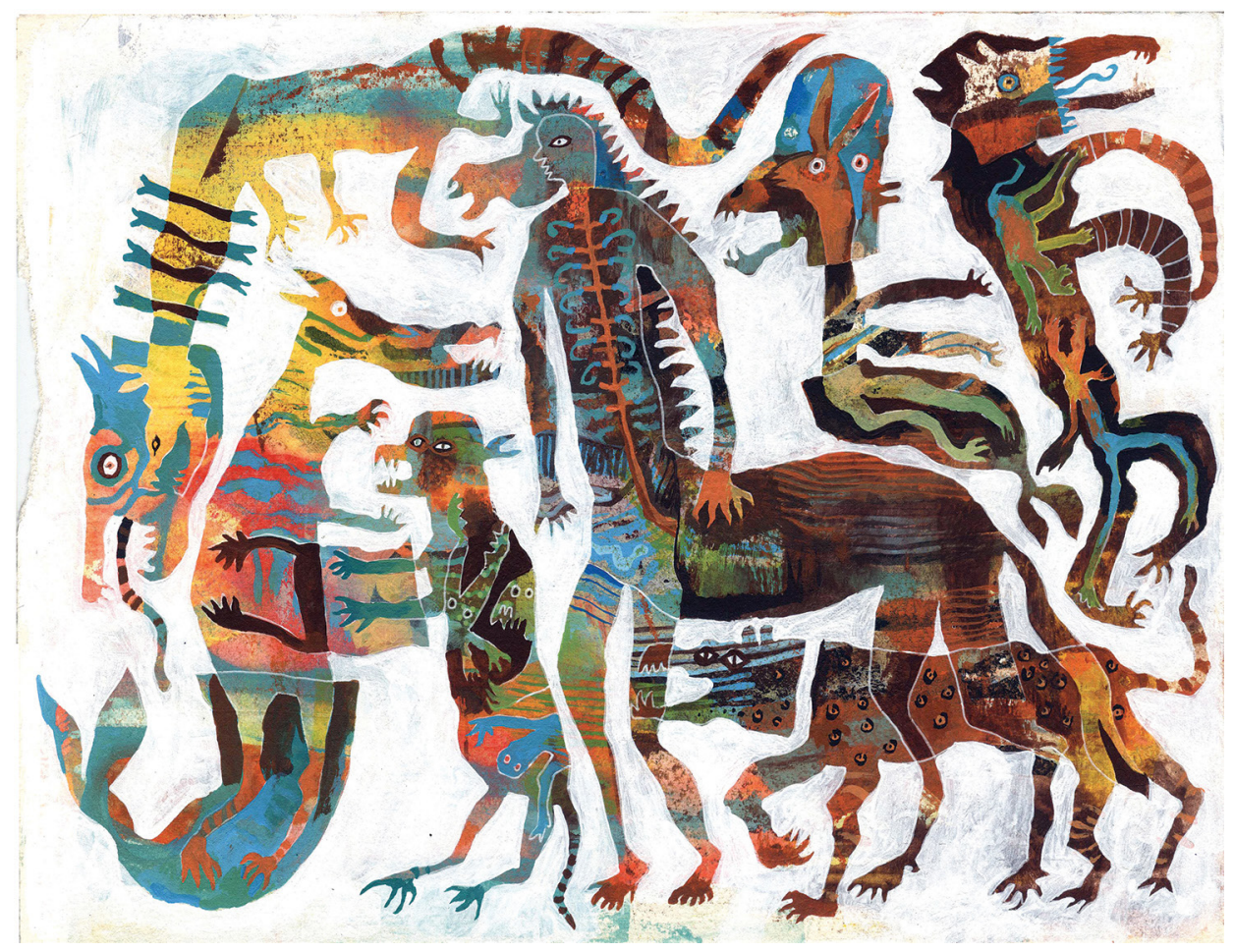

Especies híbridas, de la serie Obra pictórica (2018). Acrílico sobre papel: Carlos Alberto Badillo-Cruz. Prohibida su reproducción en obras derivadas. 
La producción de Badillo lleva implícita una reflexión sobre la figura del artista como ser creador que se libera de los rigurosos parámetros que definen al arte como tal, pero lo más significativo quizás sea que ha logrado derrocar el dominio de las imposiciones mediante sus construcciones y destrucciones, proponiendo su expresividad como signo de lo inexorable.

Carlos Badillo ha cumplido su deseo. Su magia quizás consista en transferir a cuanto plasma cierta cualidad ancestral y eterna, pues ha logrado transmutar la fragilidad de la existencia humana en una materialidad absoluta mediante la cual hace ver la totalidad y señalar el origen.

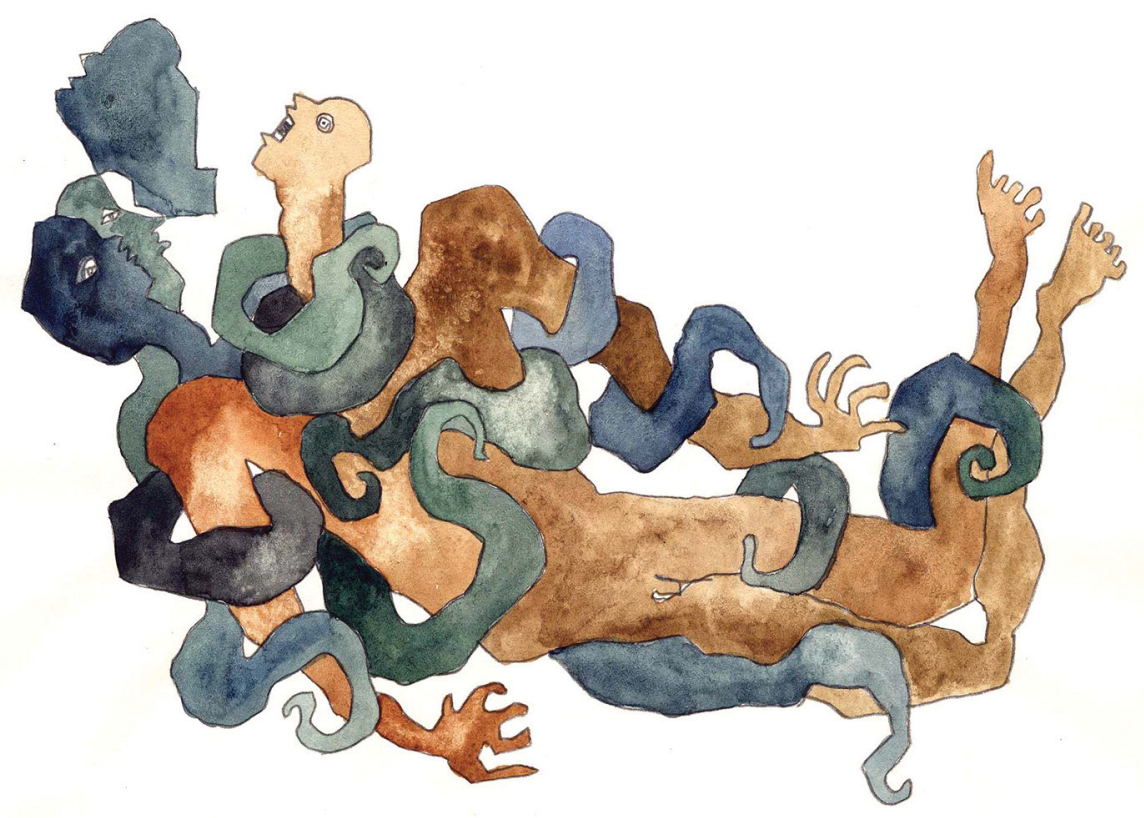

Enredos, de la serie Obra pictórica (2017). Lápiz y acuarela: Carlos Alberto Badillo-Cruz. Prohibida su reproducción en obras derivadas. 


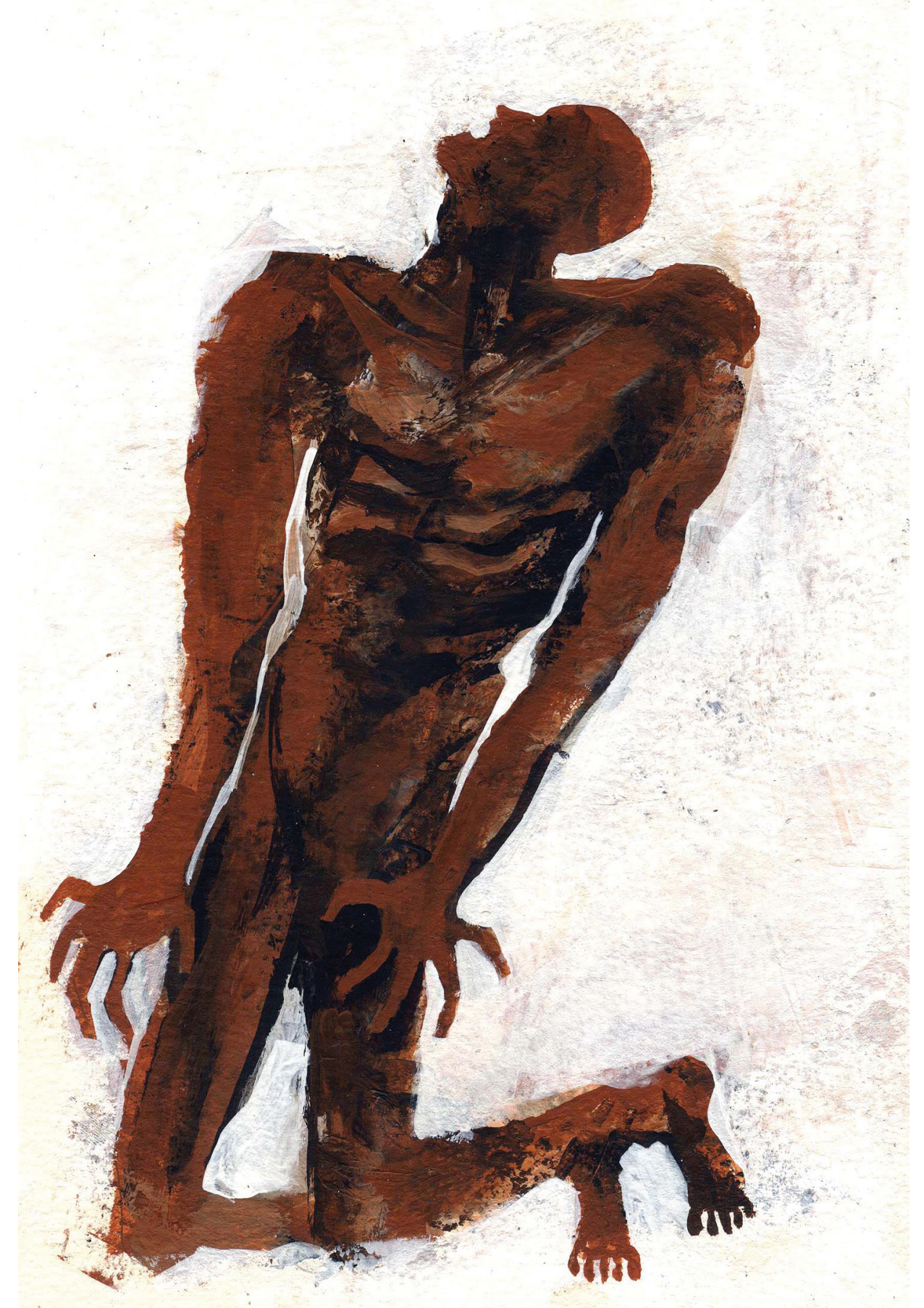

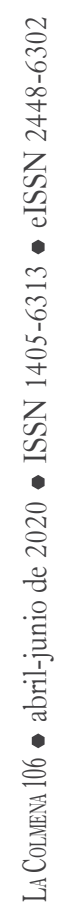

Hombre tenso, de la serie Obra pictórica (2017). Acrílico sobre papel: Carlos Alberto Badillo-Cruz. Prohibida su reproducción en obras derivadas. 


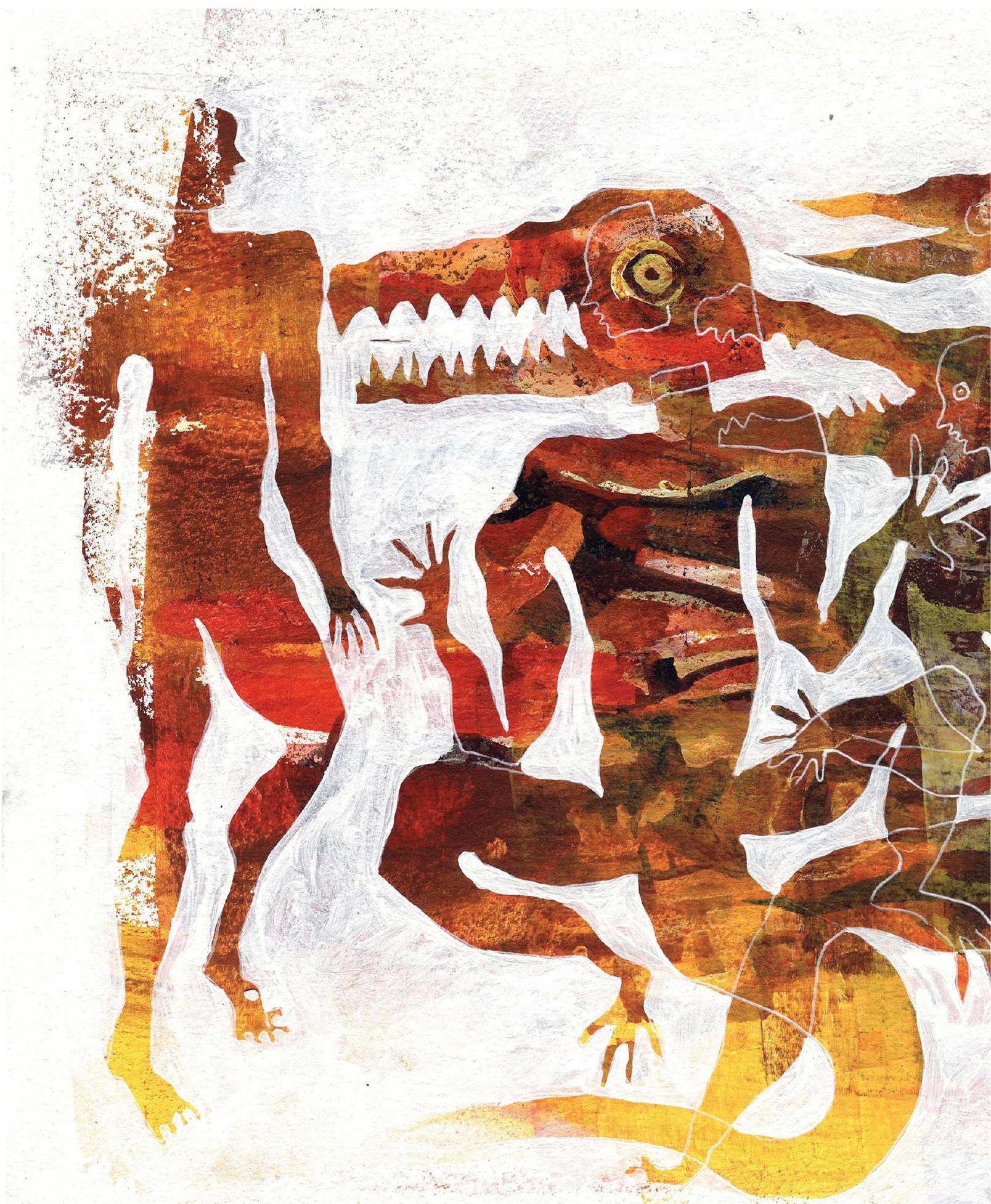

Hombres lagarto, de la serie Obra pictórica (2018). Acrílico sobre papel: Carlos Alberto Badillo-Cruz. Prohibida su reproducción en obras derivadas. 


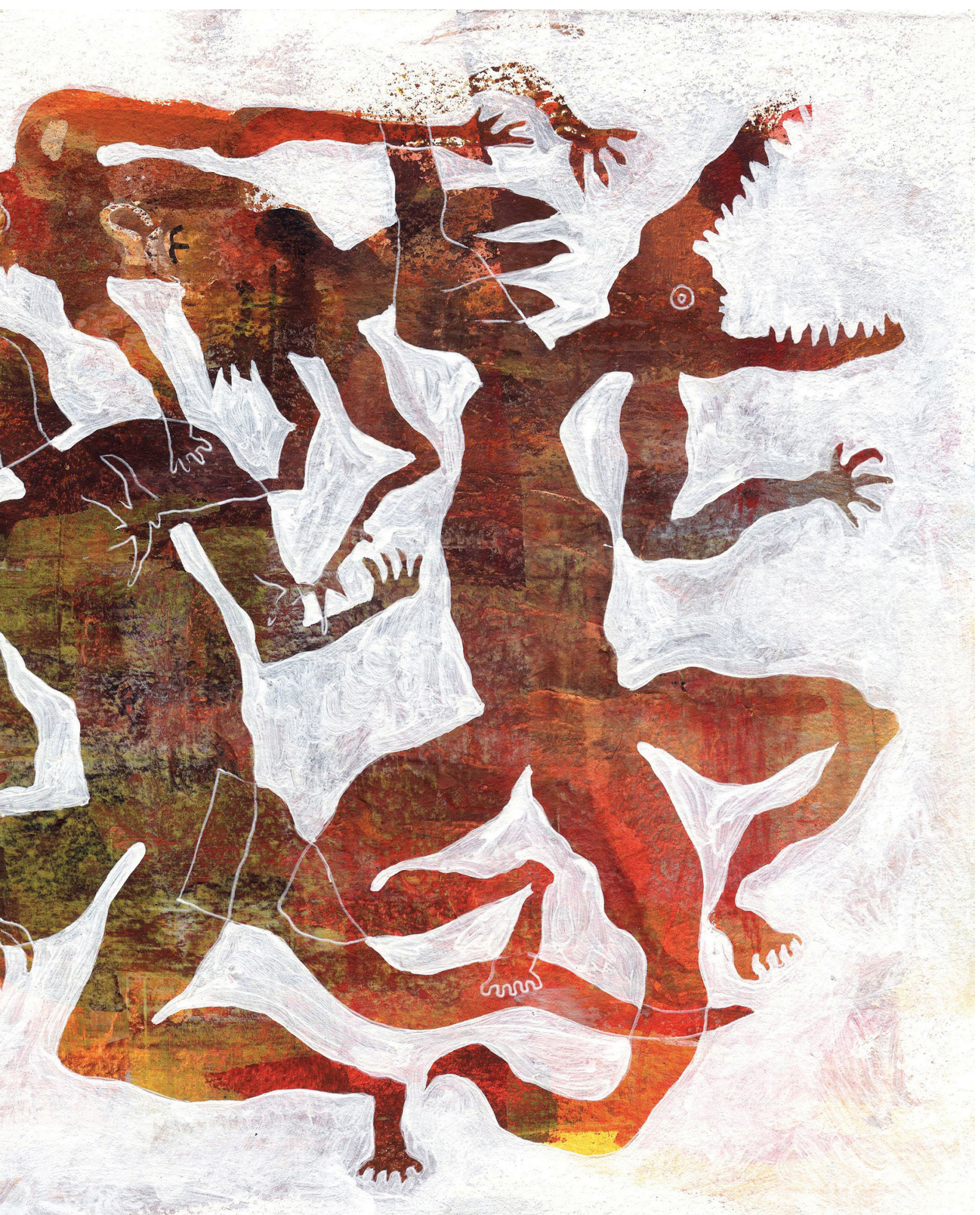

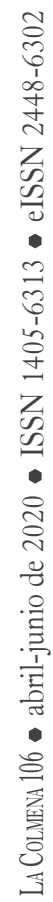




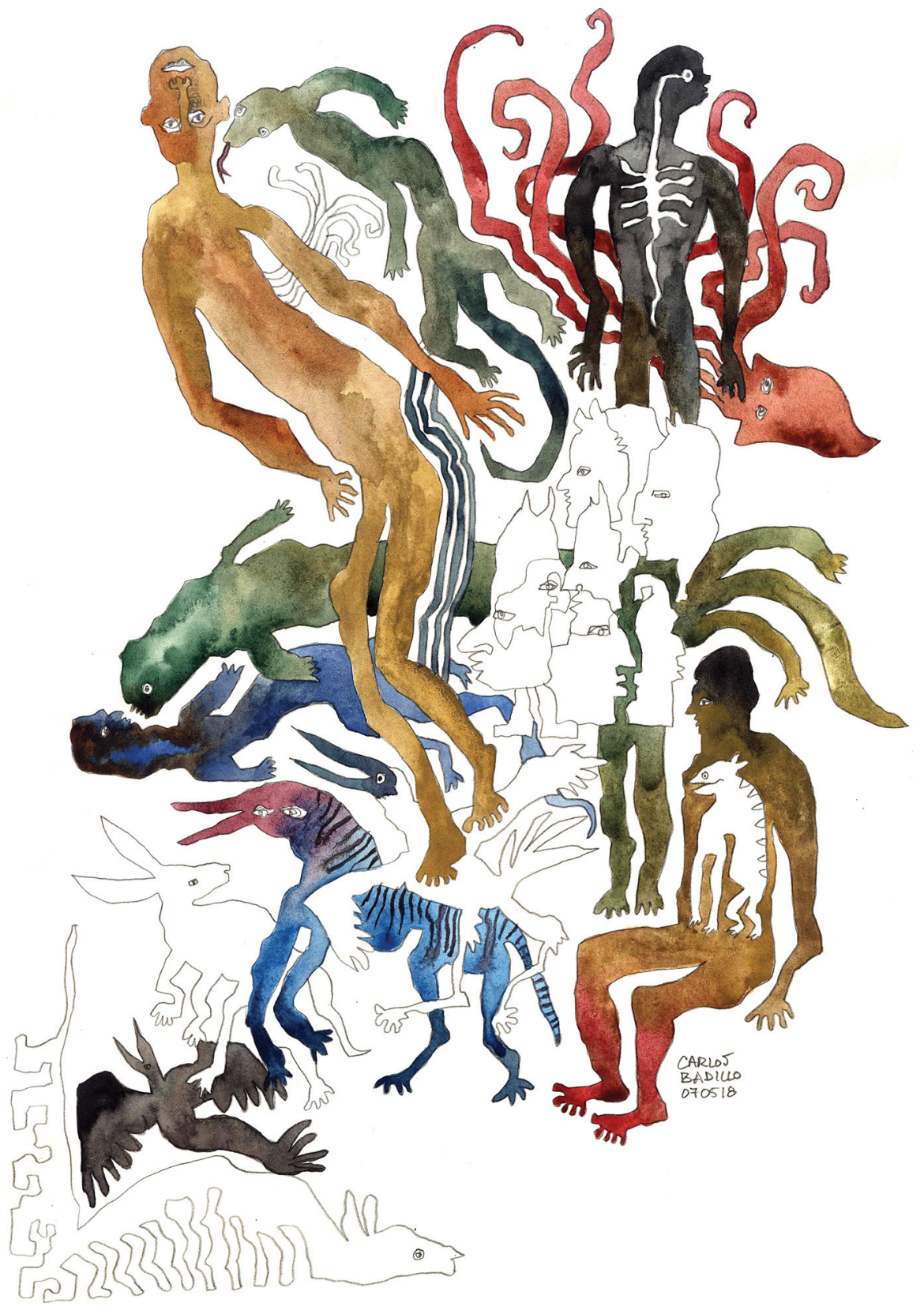

Sin título, de la serie Obra pictórica (2018). Lápiz y acuarela: Carlos Alberto Badillo-Cruz. Prohibida su reproducción en obras derivadas. 


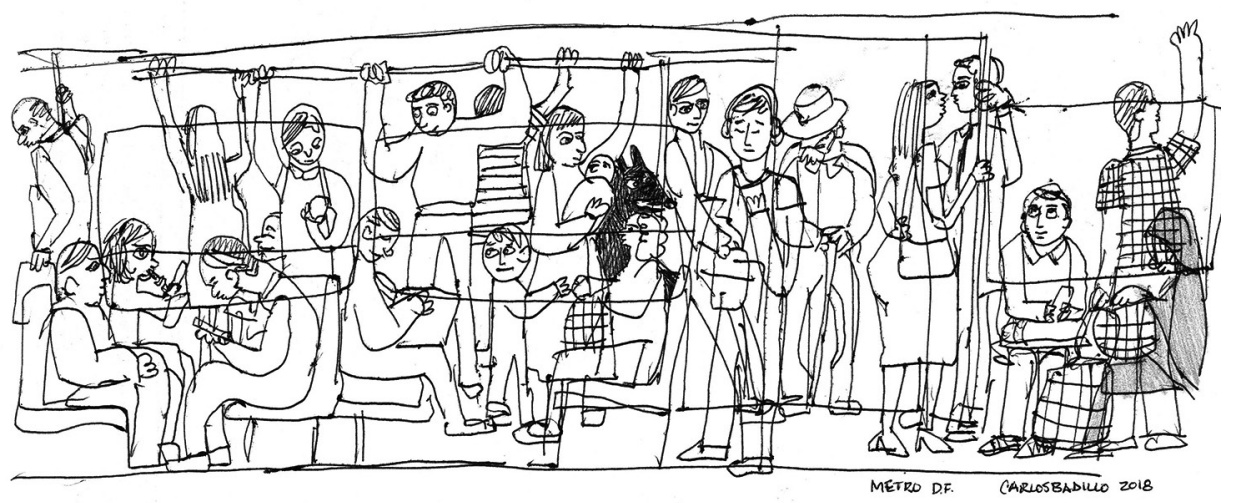

Metro DF, de la serie Dibujo simple (2017). Bolígrafo: Carlos Alberto Badillo-Cruz. Prohibida su reproducción en obras derivadas.

Carlos Badillo. Reconocido artista mexicano egresado de la Universidad Autónoma del Estado de México (UAEM), México. Ha obtenido diversos reconocimientos por la calidad y trascendencia de su trabajo en distintas áreas; como ilustrador, dibujante, cartelista, diseñador y pintor. En 2012 pintó el mural Toluca Bicentenario como parte de la conmemoración del bicentenario de la fundación de la ciudad de Toluca. Llevó a cabo el proyecto de Muralismo para la Universidad Autónoma del Estado de México, además de la serie de retratos de los doctorados honoris causa de dicha institución.

Juliana Rojas GutiérRez (Ciudad de México, 1975). Artista visual, curadora independiente y académica. Maestra en Estudios Visuales y Licenciada en Artes Plásticas por la Facultad de Artes de la UAEM. Ha sido acreedora a diversos reconocimientos nacionales e internacionales, entre ellos: fue seleccionada PECDA en la categoría Creadores con trayectoria, primera seleccionada del certamen internacional Arte Abierto MULF 2013 y 2014 en el Certamen Art Room Talent y tercer lugar de la Sexta Bienal Internacional de Arte Visual Universitario. Ha en participado en diez exposiciones individuales y más de cuarenta colectivas en México, Ecuador, Estados Unidos y Alemania. Su obra parte esencialmente del discurso relacional. Las líneas de trabajo en sus proyectos de producción e investigación giran en torno a la identidad, la vulnerabilidad y el otro. Actualmente, se desempeña como docente en el área de Pintura y Seminario Específico de Especialidad en Pintura de la Facultad de Artes de la UAEM.

Recibido: 3 de mayo de 2020

Aprobado: 5 de junio de 2020 